\title{
Study of endometrial pathology in women with abnormal uterine bleeding
}

\author{
Jessy Varghese, Jeyashambavi J.*, Deepa S.
}

\begin{abstract}
Department of Obstetrics and Gynecology, Aarupadai Veedu Medical College, Vinayaka Mission's Research Foundation, Pondicherry, India
\end{abstract}

Received: 02 October 2018

Accepted: 22 October 2018

\author{
*Correspondence: \\ Dr. Jeyashambavi J., \\ E-mail: jeenushambavi@gmail.com
}

Copyright: (c) the author(s), publisher and licensee Medip Academy. This is an open-access article distributed under the terms of the Creative Commons Attribution Non-Commercial License, which permits unrestricted non-commercial use, distribution, and reproduction in any medium, provided the original work is properly cited.

\begin{abstract}
Background: Abnormal uterine bleeding is one of the most common complaint that reproductive age women bring to their clinicians. Causes are varied and study of endometrium by dilatation and curettage with histopathological examination is an important aspect of treating patients with Abnormal uterine bleeding (AUB). The present study was done for evaluation of the histopathology of the endometrium for identifying endometrial causes of AUB.

Methods: A prospective study was conducted over a period of one year from July 2017 to July 2018 in the department of Obstetrics and Gynaecology in collaboration with the department of Pathology at Aarupadai Veedu Medical College, Puducherry. A complete clinical history, complete clinical examination, laboratory investigations, pelvic scan and endometrial biopsy were done to diagnose causes of AUB.

Results: A total of 152 cases are included. The age of the patients having AUB was ranging from 21 to 70 years. AUB was more common the age group in the age group 41-50 years (49\%) followed by 31-40 years (36\%). Majority were multiparous $(74 \%)$. Menorrhagia $(61 \%)$ was the commonest presentation. Majority of the cases showed a disordered proliferative endometrial pattern (34.2\%), followed by secretory pattern (25\%). $9.8 \%$ had polyp and $1.3 \%$ showed simple hyperplasia and $0.62 \%$ revealed complex hyperplasia without atypia and carcinoma endometrium.

Conclusions: Abnormal uterine bleeding was more common in the perimenopausal age group and majority had disordered proliferative endometrium and secretory changes. Endometrial sampling followed by histopathological examination helps us to diagnose the underlying pathology and will help in treating the patients appropriately including ruling out premalignant and malignant conditions of the uterus.
\end{abstract}

Keywords: Abnormal uterine bleeding, Endometrium, Dilation and curettage

\section{INTRODUCTION}

Abnormal uterine bleeding is the single most common complaint that reproductive age women bring to the clinicians. It is the organized sequence of endocrine signals in an ovulatory cycle that gives menstruatory predictability and consistency. However, anovulation produces an unpredictable and disorganised pattern of ovarian steroid hormone synthesis resulting in a disordered pattern of endometrium. ${ }^{1}$ AUB is bleeding that does not fall into the normal range of amount, frequency, duration and cyclicity of the normal pattern of menstrual cycle. $^{2}$ Clinical management and education of medical personal, the design and interpretation of clinical trials have been hampered by absence of a consensus system of classification of AUB. To address this issue FIGO designed the PALM COEIN in 2011.There are nine main categories which are arranged according to the acronym PALM COEIN, Polyp, Adenomyosis, Leiomyomas, Malignancy, Coagulopathy, Ovulatory dysfunction, Endometrial, iatrogenic and not yet classified. ${ }^{3}$ The study of endometrial pattern by histopathological examination 
of endometrial curettings by dilatation and curettage guides the clinician for further management of patients with AUB. In addition, it helps to rule out ominous pathology like endometrial hyperplasia and endometrial carcinoma which is on the rising trend in recent times. ${ }^{4}$ Various studies on endometrial pattern has been conducted throughout the past years with various patterns of endometrium like secretory, proliferative, disordered proliferative, atrophic, endometritis, endometrial hyperplasia and endometrial carcinoma being commonly seen.

However, with the changes in life style, increasing risk factors there is a rising incidence of AUB and people being more aware of the need to seek treatment for AUB. We attempted to study the different pathologies associated with AUB by endometrial biopsy with dilatation and curettage which offers a sensitivity of $90 \%$ in detecting endometrial abnormalities. ${ }^{5}$

\section{METHODS}

This is a prospective cross-sectional study done on patients who presented with AUB in the Department of Obstetrics and Gynaecology in collaboration with the Department of Pathology from July 2017 to July2018, after obtaining Institutional Research and Ethical Committee clearance. 152 consecutive AUB patients were enrolled in present study between the age group of 21-70 years after getting informed and written consent. Patients with isolated endometrial pathologies were only included in present study. Those with pregnancy related bleeding, leiomyomas, bleeding disorders, isolated cervical or and vaginal pathologies with bleeding, medical conditions such as thyroid dysfunctions, liver or and renal disorders and those on exogenous hormones, contraception were excluded by history, examination and investigations. A structured proforma with regard to age, parity, menstrual pattern, general and pelvic examination with appropriate investigations to rule out other causes of bleeding including pelvic ultrasonography was performed. Those patients fulfilling the inclusion criteria of having isolated endometrial pathologies were subjected to dilatation and curettage and the specimen was transported in $10 \%$ formalin to the pathology laboratory. 4-6 microns thick paraffin embedded sections were taken and stained with Hematoxylin and Eosin $(\mathrm{H}$ and E). The slides were studies by pathologists. Data collected and tabulated in Microsoft Excel. The percentages were calculated for comparison of results.

\section{RESULTS}

Total of 152 patients with AUB were included in this study. 74 patients belonged to the age group of 41-50 years (49\%), followed by 55 patients $(36 \%)$ in age group $31-40$ years. 9 patients $(6 \%)$ belonged to $21-30$ years and 14 patients $(9 \%)$ in the age group of more than 50 years (Table 1).
Table 1: Age-wise distribution of AUB.

\begin{tabular}{|lll|}
\hline Age- category & Total & Percentage \\
\hline 21-30 years & 9 & 6 \\
\hline 31-40years & 55 & 36 \\
\hline 41-50years & 74 & 49 \\
\hline$>$ 50yeas & 14 & 9 \\
\hline Grand total & 152 & 100 \\
\hline
\end{tabular}

The commonest menstrual abnormality was menorrhagia seen in 94 patients $(61 \%)$ followed by menometrorrhagia in 44 patients $(30 \%)$ and postmenopausal bleeding in 14 patients $(9 \%)$ (Table 2).

Table 2: Clinical presentation of AUB.

\begin{tabular}{|lll|}
\hline Menstrual History & $\begin{array}{l}\text { Total no } \\
\text { of cases }\end{array}$ & Percentage \\
\hline Menometrorrhagia & 44 & 30 \\
\hline Menorrhagia & 94 & 61 \\
\hline Post-menopausal bleeding & 14 & 9 \\
\hline Grand total & 152 & 100 \\
\hline
\end{tabular}

Histopathological examination revealed maximum cases of disordered proliferative endometrium 52 (34.2\%) followed by secretory endometrium 38 (25\%), proliferative endometrium in 24 patients (15.7\%), endometrial polyp in 15 cases $(9.8 \%)$, chronic endometritis in 7 patients $(4.6 \%)$, pill endometrium in 5patients (3.2\%), simple hyperplasia in 2 (1.3\%), complex hyperplasia without atypia in $1(0.6 \%)$ and one case $(0.6 \%)$ of well differentiated endometrial adenocarcinoma (Table 3).

\section{Table 3: Distribution of cases depending on histopathology.}

\begin{tabular}{|lll|}
\hline HPE & Total & Percentage \\
\hline $\begin{array}{l}\text { Disordered proliferative } \\
\text { endometrium }\end{array}$ & 52 & 34.21 \\
\hline $\begin{array}{l}\text { Secretory endometrium } \\
\text { Proliferative endometrium }\end{array}$ & 38 & 25 \\
\hline Pill endometrium & 5 & 15.79 \\
\hline $\begin{array}{l}\text { Chronic endometritis } \\
\text { Benign endometrial polyp }\end{array}$ & 7 & 4.29 \\
\hline $\begin{array}{l}\text { Atrophic endometrium } \\
\text { Simple hyperplasia }\end{array}$ & 7 & 9.87 \\
\hline $\begin{array}{l}\text { Complex hyperplasia without } \\
\text { atypia }\end{array}$ & 2 & 1.32 \\
\hline $\begin{array}{l}\text { Well differentiated } \\
\text { endometrial adenocarcinoma }\end{array}$ & 1 & 0.65 \\
\hline \begin{tabular}{l} 
Grand total \\
\hline
\end{tabular} & 152 & 100 \\
\hline
\end{tabular}

With regards to parity most of the patients with complaints of AUB were multiparous $112 \quad(74 \%)$ followed by grand multiparas $23(15 \%)$, primipara were $13(8.4 \%)$ while nulliparas were $4(3 \%)$ out of 152 cases (Table 4). 
Table 4: Parity and AUB.

\begin{tabular}{lll} 
Parity & Total & Percentage \\
Nulliparous & 4 & 3 \\
\hline Primiparous & 13 & 8 \\
Multiparous & 112 & 74 \\
\hline Grand multiparous & 23 & 15 \\
\hline Grand Total & 152 & 100 \\
\hline
\end{tabular}

Maximum number of disordered proliferative endometrium were seen in 41-50 years (23 cases), while secretory endometriums seen in 19 cases which was maximum in the among the 31-40-year olds. Other abnormalities were also seen among the 41-50 years old group in the highest number, while 21-30-year age group had the least number of endometrial pathologies (Table 5).

Table 5: Age wise distribution of AUB based on endometrial lesion.

\begin{tabular}{|c|c|c|c|c|c|}
\hline HPE & 21-30 years & $31-40$ years & 41-50 years & $>50$ years & Grand Total \\
\hline Atrophic endometrium & - & - & 4 & 3 & 7 \\
\hline Benign endometrial polyp & - & 4 & 9 & 2 & 15 \\
\hline Chronic endometritis & - & 3 & 3 & 1 & 7 \\
\hline Complex hyperplasia without atypia & - & - & 1 & - & 1 \\
\hline Disordered proliferative endometrium & 6 & 20 & 23 & 3 & 52 \\
\hline Pill endometrium & - & 1 & 4 & & 5 \\
\hline Proliferative endometrium & 2 & 8 & 11 & 3 & 24 \\
\hline Secretory endometrium & 1 & 19 & 17 & 1 & 38 \\
\hline Simple hyperplasia & - & - & 2 & - & 2 \\
\hline $\begin{array}{l}\text { Well differentiated endometriod } \\
\text { adenocarcinoma }\end{array}$ & - & - & - & 1 & 1 \\
\hline Grand Total & 9 & 55 & 74 & 14 & 152 \\
\hline
\end{tabular}

Table 6: Age wise distribution of AUB and menstrual history.

\begin{tabular}{|c|c|c|c|c|c|}
\hline Menstrual History & 21-30 years & $31-40$ years & 41-50 years & $>50$ years & Grand Total \\
\hline Menometrorrhagia & 3 & 14 & 27 & & 44 \\
\hline Menorrhagia & 6 & 41 & 44 & 3 & 94 \\
\hline Postmenopausal bleeding & & & 3 & 11 & 14 \\
\hline Grand Total & 9 & 55 & 74 & 14 & 152 \\
\hline
\end{tabular}

Menorrhagia was commonest in the age group of 41-50 years, menometrorrhagia and post-menopausal bleeding were seen in 11 cases among the age group above 50 years (Table 6).

\section{DISCUSSION}

AUB is a deviation from the normal menstrual cycle in terms of frequency, cyclicity, amount and duration. AUB has many underlying causes but isolated endometrial pathology is detected by sampling of the endometrium. The sensitivity of detecting endometrial abnormality by dilatation and curettage is reported to be as high as $96 \% .^{5}$

The highest number of cases in present study belonged to 40-50 years age group 74/152 (49\%) this compares to the studies done by Jignasha et al (33\%), Radhika G (42.6\%), Usha Devi et al $(54 \%){ }^{6-8}$ The reason may be perimenopausal depletion of ovarian follicles with infrequent ovulation leading to prolonged and excessive bleeding from thickened endometrium in the absence of progesterone. Commonest menstrual pattern was menorrhagia 94/152 (61\%) followed by menometrorrhagia $44 / 152(30 \%)$ and least were postmenopausal bleeding. Similar findings were seen in studies by Agith et al 83/152 (51.86\%) and Lithingo (49\%). ${ }^{9,10}$ Endometrial pathology showing disordered proliferative endometrium was observed in $34.2 \%$ cases, secretory endometrium in $25 \%$, these figures were similar to studies done by Gignasha et al in which $102(34 \%)$ cases had disordered proliferative endometrium and $32 \%$ were secretory. ${ }^{6}$ Disordered proliferative endometrium is a type of focal hyperplasia which lies in between the spectrum of proliferative endometrium on one hand and hyperplasia at the other end. Secretory pattern was observed in $25 \%$ of cases, this was comparable to the studies by Saraswathi et al $(28 \%)$ and Abid et al $(21 \%){ }^{11,12}$ Endometritis was seen in $4.6 \%$ however studies by Malathi et al reported $2.1 \% .^{13}$ Polyps were observed in $9.8 \%$ which is comparable to Gulia et al with $10 \%$ from 435 cases. ${ }^{14}$ Present study showed $1.9 \%$ cases of endometrial hyperplasia unlike studies by Radhika et al which had $18 \%$, the reason could be as majority of our patients belonged to the low socioeconomic strata where risk factors for hyperplasia and carcinoma endometrium 
such as obesity, nulliparity and late menopause are less prevalent. ${ }^{7}$ Atrophic endometrium as seen in $4.6 \%$ unlike Shah et al who reported $1.1 \% .{ }^{15}$ Carcinoma endometrium was seen in $0.6 \%$ while Abid et al had an incidence of less than $2 \% .^{12}$

\section{CONCLUSION}

An attempt was made to study the different patterns of endometrium in patients presenting with AUB which provides the diagnosis and basis for further evaluation and treatment. Dilatation and curettage are almost the easiest procedure to detect the causes of AUB especially precancerous lesions and malignancy itself especially in the perimenopausal and postmenopausal patients.

\section{ACKNOWLEDGMENTS}

Authors would like to thank The Dean and Management of AVMC, Vinayaka Mission's Research Foundation (Deemed to be University), Puducherry for the support provided during the study period.

\section{Funding: No funding sources}

Conflict of interest: None declared

Ethical approval: The study was approved by the Institutional Ethics Committee

\section{REFERENCES}

1. Marc A Fritz and Leon Speroff. Clinical Gynecologic Endocrinolgy and Infertility. 8th ed. Philadelphia: Lippincott Williams and Wilkins, 2011. Chapter 15: Abnormal Uterine bleeding; p.591-620.

2. Munro MG, Critchley HO, Fraser IS. The FIGO classification of causes of abnormal uterine bleeding in reproductive years. Fertil Steril. 2011;95(7):220408.

3. Munro MG, Critchley HO, Broder M., Fraser IS. FIGO working group on menstrual disorders. Int $\mathrm{J}$ Gynaecol Obstet. 2011;113(1):3-13.

4. Livingstone M, Fraser IS. Mechanism of abnormal uterine bleeding. Hum Reprod Update. 2002;8(1): 60-7.

5. Albers JR, Hull SK, Wesley RM. Abnormal uterine bleeding. Am Fam Physician. 2004;69(8):1915-26.
6. Jignasha Parmar J, Desai D. Study of endometrial pathology in abnormal uterine bleeding. Int J Reprod Contracept Obstet Gynecol. 2013;2(2):182-5.

7. Radhika G, Prayaga A. Abnormal uterine bleedingutility of dilatation and curettage in identifying isolated endometrial pathology. J Evid Based Med Healthc. 2016;3(97):2349-562.

8. Gopalan U, Rajendiran S, Karnaboopathy R. Study of endometrial histopathology in women with abnormal uterine bleeding. Int $\mathbf{J}$ Reprod Contracept Obstet Gynecol. 2017;6(3):824-8.

9. Nayak AK, Hazra K, Manju KJ. Clinico-pathological evaluation of dysfunctional uterine bleeding. Int $\mathbf{J}$ Contemp Med Res. 2017;4(4):920-24.

10. Lotha L, Borah A. Clinicopathological evaluation of abnormal uterine bleeding in perimenopausal women. Int J Reprod Contracept Obstet Gynecol. 2016;5(9):3072-4.

11. Saraswathi D, Thanka J, Shalinee R, Aarthi R, Jaya V, Kumar PV. Study of Endometrial Pathology in Abnormal Uterine Bleeding. The Journal of Obstetrics and Gynecology of India. 2011; 61(4):426-30.

12. Abid M, Hashmi AA, Malik B, Haroon S, Faridi N, Edhi MM, et al. Clinical pattern and spectrum of endometrial pathologies in patients with abnormal uterine bleeding in Pakistan:

13. Malathi BG, Ashok M. Endometrial histopathology in abnormal uterine bleeding. IP Archives of Cytology and Histopathology Research. 2017; 2(4):70-4.

14. Gulia SP, Lavanya M, Chaudhury M, Kumar SPA. Study of endometrial pathology in cases of abnormal uterine bleeding A Meta-analysis of 435 cases. J Med Sc Tech; 2013;2(3):124-29.

15. Shah RJ, Dayal A, Kothari SL, Patel SM, Dalal B. Histopathological interpretation of endometrium in abnormal uterine bleeding. Int $\mathbf{J}$ Med Sci Public Health 2014;3(4):452-56.

Cite this article as: Varghese J, Jeyashambavi J, Deepa S. Study of endometrial pathology in women with abnormal uterine bleeding. Int J Reprod Contracept Obstet Gynecol 2018;7:5037-40. 